\section{Arquitetura, Crítica Radical e Revolução no Brasil}

Architecture, Radical Criticism and Revolution in Brazil

\section{José Tavares Correia de Lira*}

*Professor Titular da Faculdade de Arquitetura e Urbanismo da Universidade de São Paulo. Seus livros mais recentes incluem O Visível e o Invisível na Arquitetura Brasileira (2017), Memória, Trabalho e Arquitetura (2013) e Warchavchik: fraturas da vanguarda (prêmio 2011 na 7ª Bienal lbero-americana de Arquitetura e Urbanismo), joselira@usp.br
Mário Pedrosa,

Sérgio Ferro,

Modernidade,

Crítica.

\section{Keywords:}

Mário Pedrosa,

Sérgio Ferro,

Modernity,

Criticism

\section{Palavras-chave:}

\section{Resumo}

miséria da crítica arquitetônica no Brasil, como nacional assinalar a nacional da arquitetura moderna local tivesse bloqueado qualquer possibilidade de escapar de perspectivas ora apologéticas, ora de censura Este artigo tem como objetivo traçar uma genealogia da crítica arquitetônica radical no Brasil, conectando alguns desafios intelectuais e políticos ao surgimento, desenvolvimento e declínio (ou persistência) da arquitetura moderna entre nós. Para tanto, retornarei a dois projetos críticos distintos: primeiro, os escritos sobre arquitetura do crítico de arte Mário Pedrosa (1900-1981), que, nas décadas de 1950 e 1960, buscava compreender o lastro cultural da arquitetura moderna no Brasil; em segundo lugar, um discurso mais comprometido profissionalmente, levantado entre os anos 1960 e 1970 pelo arquiteto Sérgio Ferro (1938-), para quem o papel sociotécnico do projeto deveria ser testado diante da modernização material brasileira. Ao fazer isso, espero poder tocar alguns dos dilemas críticos contemporâneos em face da disciplina, sua história e sua atualidade intelectual e política. usjt

arq.urb

Recebido: $17 / 06 / 2020$ Aceito: 30/09/2020 número 29 | set - dez de 2020

tips://doi.org/10.37916/arq.urb.vi29.484

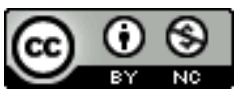

Since the 1950s, it became a national commonplace to remark the misry of architectural criticism in Brazil, as if the international magnetism of local modern architecture would have blocked any possibility to evade either apologetic or admonitory perspectives. This article aims at sketching a genealogy of radical architectural criticism in the country by connecting a few intellectual and political challenges to the emergence, development and decline (or persistence) of modern architecture among us. In order to do so, I will return to two different critical projects: irst, the writings on architecture by art critic Mario Pedrosa (19001981), whom, in the 1950s and 60s, was in search of a cultural framework to modern architecture in Brazil; secondly, a more professionally committed discourse raised from the 1960 s to the 1970 s by architect Sergio Ferro (1938-) to whom the socio-technical role of design should be tested in face of Brasilian material modernization. By doing so, I hope to be able to touch some of the contemporary critical dilemmas in 


\section{Arquitetura, Crítica Radical e Revolução no Brasil}

Em 1957, enquanto Brasília estava sendo construída, o arquiteto Sylvio de Vasconcellos (1916-1979) publicou um artigo sobre "Crítica de Arte e Arquitetura" na revista $A D$ Arquitetura e Decoração. A ausência de uma crítica de arquitetura no Brasil era para ele motivo de preocupação. A circunstância derivava de múltiplas razões, incluindo a origem autodidata dos críticos arquitetura locais, sua perplexidade diante da repentina explosão da arquitetura moderna no Brasil e suas imediatas filiações às fortes exigências de legitimação que o momento infundia. Para ele, uma certa unanimidade parecia ter sido produzida entre os críticos e de tal maneira que qualquer "análise isenta, desapaixonada, a pesquisa, as tentativas de anotar resultados brilhantes ou menos favoráveis, enfim a crítica em sua real acepção, tornou-se uma temeridade, uma ofensa, uma posição contra, um desserviço à arte, uma prova de incapacidade mental ou emocional e uma provocação" (Vasconcelos, 1957). Essa atitude por certo teria desempenhado um papel importante na recusa precoce da arquitetura de estilo e do funcionalismo estrito. Mas, estava na hora - pensava ele - de se afastar de uma visão dogmática, que bloqueava a arquitetura contemporânea brasileira de um exame mais rigoroso. Crítica nunca deveria confundir-se com autojustificação, nem se limitar a formas meramente visuais de apreciação. Afinal, arquitetura não era uma arte do visível, mas de experiências e de organizações espaciais voltadas ao atendimento de tais ou quais estilos de vida.

Vale notar que uma tal chamada à crítica surgia em um momento no qual o modernismo já havia se difundido por todo o país, estabelecendo-se como paradigma pedagógico, profissional e imobiliário, além de um dos grandes produtos culturais brasileiros. Como se sabe, desde a década de 1940, a arquitetura moderna brasileira ganhara atenção considerável em toda parte, sendo internacionalmente aclamada como uma das alternativas mais criativas aos rígidos padrões do movimento moderno. Do Brasil aos Estados Unidos, na Europa e por toda a América Latina, críticos, curadores, editores e historiadores mostravam-se fascinados com sua inteligência regional, originalidade formal e ousadia técnica (Martins, 1999; Liernur, 1999; Xavier, 2003; Cappello, 2006; Tinem, 2006). Nesse movimento, um certo número de obras muito sofisticadas passavam a integrar o cânone internacional para modelar uma contribuição especificamente brasileira ao modernismo arquitetônico como um todo, configurando uma narrativa coerente sobre suas origens e desenvolvimento, sua difusão e relevância, e mais adiante sobre sua decadência, alguns anos após a conclusão de Brasília.

Ao mesmo tempo, a década de 1950 coincide com as primeiras restrições mais sonoras ao formalismo brasileiro, afetando a auto-estima local e, eventualmente, estimulando novos pontos de vista. No Rio de Janeiro, por exemplo, onde as bases da arquitetura moderna brasileira haviam se estabelecido, essa atitude se refletiu em um relativo impulso intelectual e institucional de racionalização, de certa forma ecoando a crítica lançada em 1953 por Max Bill contra sua suposta frivolidade (Nobre, 2008; Fiammenghi, 2020). Em São Paulo, influentes revistas de arquitetura - como a própria $A D$, que passou a referendar a arte concreta depois de 1955; Habitat, dirigida de 1950 até 1954 por Lina Bo e Pietro Maria Bardi; e Acrópole, cada vez mais assumindo um investimento local de vanguarda em discursos técnico-sociais - adotariam posições dissonantes no debate nacional, que mais tarde viriam a ser articuladas em torno de uma tal escola brutalista de São Paulo (Zein, 2005; Stuchi, 2007; Junqueira, 2009; Mesquita, 2011; Dedecca, 2012; Silva, 2017). Até o próprio Oscar Niemeyer, que, em 1958, reconheceu a sua indiferença ao lastro social da arquitetura, admitiria ter sido levado "a adotar uma tendência excessiva para a originalidade" em muitos de seus primeiros projetos, em detrimento do senso de economia e lógica que eles requeriam. (Niemeyer, 1958)

\section{Uma tendência crítica}

Apesar da avaliação de Vasconcellos e da inegável hegemonia de representações pró-modernas e nacionais no período, parecia que um novo ambiente crítico estava emergindo por todo o país. E nem sempre ele se mostraria imparcial, nem desapaixonado. Em parte, era composto de uma primeira geração de críticos de arte profissionais, começando com Mário de Andrade (1893-1945) na década de 1920, que, em 1944, diante da exposição "Brazil Builds" no MoMA (Goodwin, 1943) e do prestígio do fascismo em São Paulo, rejeitara as análises formais em arquitetura, inclusive enquanto expressão de uma estética da vontade (Andrade, 1944). Mas, também, com Mário Pedrosa (1900-1981), Geraldo Ferraz (1905-1979), Mário Barata (1921-2007) e Flavio Motta (1923-2016), todos eles, inevitavelmente, atraídos pelo cativante debate arquitetônico, que tinha recentemente adquirido uma relevância sem precedentes no cenário cultural brasileiro. Em parte, era formada por arquitetos praticantes, alguns dos quais, inclusive, protagonistas como Lucio Costa (1902-1998), Oscar Niemeyer (1907-2012), Lina Bo Bardi (1914-1992), bem 
como João Vilanova Artigas (1915-1985), que, na verdade, estava à frente do mais exigente engajamento ético-político contra duas estéticas opostas, que ele definia como "Apolínea" e "Dionísica", avesso a todas as formas de comercialismo profissional, à especulação imobiliária e ao comando yankee dos desenvolvimentos arquitetônicos (Artigas, 1951; 1954). Em suma, um momento de chamada à crítica em face da realidade, que viria a atrair gerações de arquitetos mais jovens, que então começavam a enveredar por carreiras mais especializadas, como teóricos, historiadores ou preservacionistas, como o próprio Vasconcellos, Edgar Graeff (1921-1990), Carlos Lemos (1925-) e Sergio Ferro (1938-).

Seria impossível revisar aqui toda essa história da crítica arquitetônica no Brasil. Suas variadas vertentes teóricas e agendas poéticas, políticas e culturais, as redes institucionais e intelectuais nas quais ela se apoiava e os itinerários individuais singulares que ela projetou, são multifacetados e ainda estão por ser examinadas em suas minúcias e em conjunto. Ao destacar aqui algumas perspectivas individuais exemplares, apenos quero endereçar uma certa inclinação que me parece ter desempenhado um papel sui-generis e muito produtivo na crítica arquitetônica brasileira ao longo de todo o século XX: sua linhagem radical. Acredito que reconectar algumas interpelações críticas locais à arquitetura moderna produzida no Brasil entre as décadas de 1950 e 1970 pode ajudar a esclarecer certas posições peculiares no âmbito da crítica internacional de arquitetura naqueles anos.

Por tendência radical, refiro-me de maneira geral ao conjunto de ideias e atitudes que resistem a um inconsciente coletivo excessivamente reacionário, que, diferentemente de outros países latino-americanos, tem prevalecido fortemente no Brasil entre as elites políticas, letradas e profissionais. Ela eventualmente moldaria uma tradição peculiar - apesar de marginal - altamente sensível aos problemas socioculturais urgentes no país e a seus dilemas estéticos correspondentes, tendendo a pensá-los como um todo, seja na escala da nação, seja na escala global da modernidade. Intensamente enraizada nas classes médias ilustradas das cidades, essa tradição radical na crítica frequentemente tendeu a identificar-se com as questões postas pelos trabalhadores e as camadas populares, por vezes assumindo uma plataforma revolucionária. É claro que o crítico radical é "sobretudo um revoltado, e embora o seu pensamento possa avançar até posições realmente transformadoras, pode também recuar para posições conservadoras" (Candido, 1995: 266). Operando no interior de uma sociedade subdesenvolvida, cheia de resquícios coloniais, escravocratas e oligárquicos, e alvo recorrente de interferências militares, o radicalismo brasileiro, apesar de sempre politicamente orientado e, mesmo revolucionário, parece ter por vezes apontado para objetivos moderados. Candido não se referia a nenhum de nossos personagens em seu ensaio, mas à obra de Joaquim Nabuco, Manoel Bonfim e Sérgio Buarque de Holanda. Seja como for, é importante destacar esse toque de ambiguidade que permeia o senso radical de compromisso com causas maiores e sua eventual transigência para com narrativas reconciliadoras. Pois o encontraremos também enraizado entre os arquitetos e críticos da arquitetura brasileiros na busca por identidade ou autonomia cultural, em deveres relacionados com a construção do Estado-nação, bem como em muitas das respostas à causa do desenvolvimento ou a promessas de autossuficiência política, inclusive de coloração nacionalistas ou populistas.

Mário Pedrosa, entre as décadas de 1950 e 60, e Sérgio Ferro, da década de 1960 à de 70 - a quem poderíamos sugerir também o nome de Otília Arantes (1940-) a partir dos anos 1980 - parecem ao meu ver representar alguns dos esforços intelectuais mais proeminentes de construção de um front radical e revolucionário na crítica arquitetônica no Brasil contemporâneo. Ao avançar os limites de certo radicalismo, e oscilando entre vanguarda artística e vanguarda política, cada um deles a seu modo e, por vezes, de forma interligada, parecem ter extraído da teoria marxista e da experiência dramática local, vistas de um ponto de vista ao mesmo tempo nacional e contemporâneo (Schwarz, 1999), efeitos intelectualmente originais de desprovincianização (Candido, 1967; 1973; Chakrabarty, 2000) para o entendimento tanto da produção arquitetônica no Brasil, como da modernidade arquitetônica e crítica em geral

\section{Abstração e Utopia}

Em seu artigo, Sylvio de Vasconcellos também se refere à análise de Mário Pedrosa sobre crítica de arquitetura. Diferentemente do arquiteto, de fato, mais cedo naquele ano, o crítico de arte havia reiterado em um artigo específico sobre "Arquitetura e Crítica de Arte" a sua censura ao funcionalismo arquitetônico, elogiando a rebeldia dos arquitetos modernos brasileiros ao mandar - em suas próprias palavras - "a dieta funcional às favas". Para Pedrosa, era tempo de superar uma "crítica de arquitetura inibida, complexada" e entregar-se à "sua tarefa específica, que é a apreciação estética" (Pedrosa, 1957a). 
Desde 1944, quando Pedrosa publicou seus primeiros artigos sobre a retrospectiva individual de Alexander Calder (1898-1976) no MoMA de Nova York um ano antes, ele tinha se engajado em um deslizamento radical rumo à arte abstrata e à crítica estética (Pedrosa, 1944; Arantes, 1991). Desde então, algumas das questões fundamentais do período começaram a emergir em seus escritos: as relações entre arte e tecnologia, ou entre arte e utopia, as ligações entre visualidade e percepção, o debate abstração versus realismo, os temas da integração e da síntese das artes, entre outros. É importante lembrar que, apesar de naqueles anos engajar-se na causa da autonomia (Gabriel, 2017), Pedrosa iniciara sua carreira como crítico da arte em 1933 com um artigo sobre "Käthe Kollwitz e as tendências sociais na arte", no qual propunha uma espécie de "arte do proletariado" capaz de converter a vida emocional e coletiva do proletariado em matéria de percepção visual (Pedrosa, 1933).

Com efeito, a prolííca colaboração de Pedrosa em periódicos diversos ao longo da vida oscilaria entre arte de vanguarda e trotskismo político. Em 1942, diante dos murais de Candido Portinari (1903-1962) para a Biblioteca do Congresso em Washington, D.C., que haviam sido pintados com temas retirados à história brasileira, Pedrosa, um forte opositor do realismo socialista de Stalin, desviaria de suas representações marcadamente nacionais. Em meio a uma sofisticada análise visual da série, ele se colocaria em favor de categorias estéticas de julgamento da obra em clara reação aos temas figurativos nela representados (Pedrosa, 1947). Seus comentários aos murais de Portinari são bastante eloquentes a esse respeito:

"Por processos afastados de qualquer receita, ele tende ao que se poderia chamar de desmitologização de seus ícones, de suas imagens, de suas paisagens, numa fuga às contingências externas, de meio e de tempo, nacionais ou não, e come os dedos de seus pretos, desconcretiza as formas de seus seres, intensifica a oposição violenta dos contrastes, multiplica os sinais geométricos numa ânsia de abstração." (Pedrosa, 1943, 19).

Valor estético e compromisso ético-político poderiam ser assim reconciliados "no terreno dos procedimentos artísticos" (Arantes, 1991, p. 31). Os problemas colocados ao conceito de arte por Calder afiguravam-se como uma resposta adequada a uma plataforma social, ou mesmo "vital", de abstração: a ideia de trabalho inacabado, questões de suspensão, surpresa ou de estímulos espaciais, problemas de organização de movimento e contraste, de relações variáveis de formas no espaço eram vistos como um modo de apreender ao mesmo tempo o valor estético da obra de arte e o seu papel específico na sociedade. "Desencarnadas de qualquer convenção, ou função externa", as formas de Calder poderiam então evitar qualquer sugestão naturalista ou realista (Pedrosa, 1944, 61), e, ao mesmo tempo, ligarem-se intimamente à vida coletiva. Sua característica prosaica não fugia do contato direto com as pessoas, que a princípio deveriam mover, tocar e empurrar os Estabiles e Mobiles do artista. Eles eram ademais supostamente projetados para ocupar praças públicas e jardins com "coisas nunca vistas, de sugestões de mundos e bichos desconhecidos, de fábulas novas, de sonhos, de imaginações e silêncios revivificantes". Eles realmente evocavam "motivos de remotas eras geológicas ou de presságios de coisas ainda por existir", mas, de tal modo que nós poderíamos chamá-los de "arte democrática porque pode ser feita de qualquer troço, cabe em qualquer lugar, a serviço de qualquer condição, nobre, rara ou usual", revitalizando e transformando "a vida de todos os dias e o ambiente, informe e feio, grosseiro e triste, em que vegetam as grandes massas populares embrutecidas" (Pedrosa, 1944, 65). Uma arte revolucionária, portanto, jamais poderia ser reduzida a simples alimento cultural das massas para que pudessem executar a revolução política. Sua missão não era competir com a cultura e os meios de comunicação de massa. Ela era outra: especificar e isolar o que Pedrosa via como "ângulos inéditos ou pouco percebidos dessa visualidade em constante movimento", capaz de levar a uma "revolução da sensibilidade" (Pedrosa, 1952a, 98).

Em seu primeiro artigo sobre arquitetura, "Espaço e Arquitetura", publicado em 1952, Pedrosa justamente insistiria nesse papel revolucionário da arte arquitetônica. Remetendo-se ao livro "The Architecture of Humanism", de Geoffrey Scott, e a seu apreço pelo espaço como categoria suprema da crítica arquitetônica, ele reafirma, seguindo o crítico inglês, o conceito de espaço como um "nada", em outras palavras, como "uma pura negação do que é sólido" (Scott, 1914, 226). Sua incompatibilidade com nosso foco tradicional na matéria, teria feito com que o espaço viesse a ser frequentemente negligenciado. Entretanto, "delimitar um espaço é o objetivo da construção; quando construímos, nós não fazemos senão separar uma quantidade conveniente de espaço, fechá-lo, protegê-lo, e toda arquitetura nasce dessa necessidade". Espaço e movimento, "espaço como liberdade de movimento" e o apelo do arquiteto ao movimento eram as principais estratégias 
"para produzir um certo estado de espírito naqueles que nele entravam", uma espécie de "consciência física" do espaço, para provocarem seus instintos a se adaptarem aos espaços nos quais seus corpos se projetam (Scott, 1914, 227). Para Pedrosa, esse caráter orgânico, físico, corpóreo, material do espaço moderno alinhava-se com a civilização contemporânea:

"Ela anseia, ao contrário, por espaços mais livres, maleáveis, ilimitados, como se estivéssemos todos à espera misteriosa de uma nova dimensão para além das três euclidianas. (...) A revolução arquitetônica não é, pois, puramente externa. Ao contrário. Ela se dirige para fora e para dentro do edifício, onde permite que, pela primeira vez, desde as épocas pré-históricas, quando o homem primitivo vivia no interior da terra, tenhamos consciência física do avesso do espaço, da sua existência física". (Pedrosa, 1952b, 253)

Um tal conceito de espaço ilimitado, maleável e plástico, a ser tatilmente apreendido no movimento; tal ideia de uma consciência física de um vazio espacial visto como o avesso do edifício, ecoa, certamente, seu entusiasmo pela obra de Calder, que, nesse sentido, bem poderia ser relacionada à arquitetura de Niemeyer. Mas, se a referência a um dos arautos da autonomia arquitetônica como Scott era certamente pouco ortodoxa (Gabriel, 2017, 108-112), ela não era casual. Afinal, o papel do crítico da arte deveria ser indagar o quanto uma obra de arquitetura corporificava impulsos estéticos ou não (Pedrosa, 1957b), ou antes, "perceber, simples e imediatamente, a arquitetura como tal” (Pedrosa, 1957c, 278). É importante observar que, assim procedendo, o crítico militante não evitaria falar de si, "não para 'defender-se', mas para explicar-se" na luta livre da crítica; em outras palavras, o crítico radical não evitaria de modo algum ser "sectário, partidário, político", na procura de um ponto de vista capaz de abrir novos horizontes (Pedrosa, 1957d).

$\mathrm{Na}$ altura dos anos 1950, Pedrosa havia definitivamente alcançado uma posição das mais ativas e influentes no sistema de arte brasileiro, liderando importantes movimentos artísticos, falando e publicando intensamente, difundindo ideias inéditas, insurgentes, acompanhando jovens artistas, assumindo a curadoria de algumas das mais notáveis exposições de arte do período e se tornando um nome proeminente da Associação Internacional de Críticos da Arte (Arantes, 1995). Em uma palestra organizada e publicada em Paris em 1953 - poucos meses depois da crítica bombástica de Bill à obra de Niemeyer - ele se debruçou sobre a produção arquitetônica moderna no Brasil de maneira geral. Destacando perante o público francês o "estado de espírito revolucionário" que vinha ascendendo no país desde a década de 1930, Pedrosa retomou a ideia de Lucio Costa (1952) de um influxo europeu inicial na base de seu surgimento repentino de forma a situar a relevância internacional de algumas de suas peculiaridades projetuais: o jogo criativo de superfícies, volumes e espaços; o uso inventivo do brise-soleil, não apenas no controle de luz e calor mas na animação e, por vezes, na criação de efeitos pictóricos e gráficos nas fachadas; os jogos de formas livres, ainda que às expensas do programa; a integração entre espaço interno, o entorno e a paisagem; a leveza de soluções estruturais e a combinação precisa de materiais. Para ele, os jovens "jacobinos" brasileiros do purismo arquitetônico, confiantes nas virtudes democráticas da produção em massa, tinham assim, aparentemente, embarcado na pesquisa teórica de um acordo entre arte e técnica.

Para Pedrosa, a adoção imediata das ideias revolucionárias de Le Corbusier no Brasil estava, na verdade, em sintonia com o clima contraditório e de instabilidade pelo qual passava o país com a grande crise de 1929 e a revolução de 1930. Diferentemente da França, onde faltava "fé" na produção em massa, e do México, onde a revolução enraizara-se em reivindicações indígenas por reparação contra o colonizador branco; o Brasil não contava com uma civilização antiga nem com com fortes tradições étnicas ou nativistas de dissidência. Ao contrário, se "a terra era ainda virgem", e se "estávamos condenados ao moderno", como ele viria a colocar posteriormente, a afirmação local de um regime totalitário se mostraria uma oportunidade vantajosa para o engajamento dos arquitetos em um esforço nacional de modernização (Arantes, 1991, 84-86). Mas, se "os novos construtores utilizaram-se do poder de ação dos ditadores para pôr em prática suas ideias" (Pedrosa, 1953a, 259), uma contradição emergia entre o compromisso social e racional da nova arquitetura e o gosto local do suntuoso e de "formas gratuitas que se tornaram moda", alinhados com as preocupações do regime com autopropaganda e representações de força. Como "ilhas" ou "oasis" caprichosos na vastidão do país, trabalhos como o Ministério da Educação e Saúde ou o conjunto de Pampulha, em conformidade com as aspirações de grandeza da ditadura, jamais teriam alcançado qualquer efeito orgânico ou vital no território (Pedrosa, 1953b, 266), nem enfrentado corretamente os problemas fundamentais da habitação social, das favelas ou do caos urbano no Brasil. Em vez disso, reforçavam a cisão local entre intenções e possibilidades no interior da arquitetura moderna. 
Apesar de ser fortemente crítico de Niemeyer - "não se sabe se diletante porque cético, ou cético porque diletante" (Pedrosa, 1958a, 290) -, Pedrosa certamente guardaria certo otimismo quanto à arquitetura brasileira. Para ele, os trabalhos de Burle Marx e Reidy eram particularmente expressivos de uma era democrática em ascensão e melhor exemplificavam seus valores estéticos, ao reintegrar princípios socialmente orientados no ambiente local. Talvez devido a suas próprias convicções acerca das vantagens do atraso brasileiro, na possível conversão do negativo em positivo, é que possamos entender o seu entusiasmo inicial com Brasília. Naturalmente, leitor interessado que era nas obras de Trotsky, Lenin e Rosa Luxemburgo, ele estava perfeitamente consciente do abismo entre as condições locais e aquelas vigentes em sociedades avançadas, a reiterar permanentemente o imperialismo, o colonialismo e a dependência, assim como a emulação do aparato civilizacional moderno. Mas, como reconheceu Otília Arantes, ele era "também um intelectual brasileiro fiel à tradição culturalista de interpretação e acomodação de nossas singularidades" (Arantes, 1991, 92).

Apesar de sua aparente desconfiança política em relação a Kubitschek, Brasília cedo surgiria para Pedrosa como uma síntese potente da dimensão utópica de uma vontade nacional de criação, um formidável oásis civilizatório, um transplante abstrato Worringeano para uma nação sem passado (Pedrosa, 1957e, 303-306): "uma passagem da utopia ao plano" (Pedrosa, 1958b, 319), "uma hipótese de reconstrução de todo um país” (Pedrosa, 1959, 334). É verdade que ele nunca apoiaria o experimento sem criticá-lo: muito do caráter híbrido e incerto da cidade, programaticamente vago e ligeiramente anacrônico amparava-se em um apelo místico de Lúcio Costa a ambas as imagens de uma cruz, evocativa do assentamento colonial, e de um avião, para Pedrosa uma espécie de mandinga: "na esperança de que a vitalidade mesma do País lá longe, na periferia, queime as etapas, e venha de encontro à capital-oasis, plantada em meio ao Planalto Central, e, então, a fecunde por dentro" (Pedrosa, 1957e, 307).

Anos mais tarde, enquanto o processo político nacional mais uma vez recaía em um regime totalitário, ele se tornaria muito mais exigente acerca dessas esperanças. Se Brasília havia preparado o caminho para uma cidade ideal como verdadeira obra de arte; se ela havia criado uma perspectiva física e espiritual para todo o Brasil, somente no dia em que se tornasse "a capital verdadeira de um Brasil renovado", ela poderia, de fato, corresponder à plataforma econômica, social, ética e cultural mais elevada a que postulara. Só então, do alto dessa plataforma, os desníveis poderiam ser desmanchados:

"o regional será subsumido no nacional, o nacional subsumido no internacional. Um Brasil outro que o de hoje terá a sua mensagem, seu acento, seus fonemas, seus modos, inclusive sua arte, perfeitamente inteligíveis a outras mensagens, dentro do sistema semiológico único de uma comunicação mundial" (Pedrosa, 1973, 276).

Até lá, contudo, ainda havia um longo caminho a percorrer. De fato, em 1973, a cidade já havia sido tomada pelos militares e Pedrosa estava vivendo no Chile como exilado político, acusado pelo governo brasileiro de vilipendiar a nação.

\section{Labor, Trabalho e Emancipação}

Até o fim da década de 1950, Sérgio Ferro estudava arquitetura na Universidade de São Paulo, logo iniciando uma curta, porém notável carreira profissional. Em 1963, um ano após tornar-se professor assistente de história da arte na Faculdade de Arquitetura e Urbanismo da USP (FAU-USP), ele assinou um artigo com Rodrigo Lefèvre (1938-1984), seu contemporâneo e parceiro de trabalho, intitulado "Proposta inicial para um debate: possibilidades de atuação". Manifestando uma abordagem crítica da prática, os dois jovens arquitetos propunham discutir os dilemas enfrentados por qualquer arquiteto atuando em um país subdesenvolvido que vinha florescendo economicamente desde o final da Segunda Guerra e que tinha recentemente inaugurado nova capital. De certo modo, eles viriam ali a reformular a leitura de Pedrosa acerca das contradições da arquitetura moderna brasileira. Para eles, qualquer ação arquitetônica no Brasil era inevitavelmente desafiada pelo que chamavam de "uma situação-no-conflito", a saber, um conflito entre a expansão das forças produtivas e as necessidades vitais do povo. A despeito de quaisquer qualidades estéticas ou técnicas atingidas pela arquitetura local, graves contradições sabotavam permanentemente os seus princípios sociais e como tal deveriam ser testadas criticamente em face das grandes estruturas de produção, alienação e mercantilização que permeavam a arquitetura. Afinal, ao deixar de lado as reais necessidades dos produtores e consumidores primários das obras edificadas, os arquitetos brasileiros - apesar de suas convicções políticas - vinham sistematicamente negligenciando as reais demandas espaciais da população (Ferro e Lefèvre, 1963). Na verdade, vinham sistematicamente operando com o "falseamento da profissão", promovendo "o conceito de arquitetura como artigo de luxo", e, como tal, confessando o grau de aburguesamento a que a pro- 
fissão tinha se rendido (Ferro, 1965, 39).

Ferro pertence a uma geração de arquitetos marcada pela inauguração e a crítica de Brasília e da ideologia correlata do desenvolvimento, que o levaria a uma ruptura precoce com as pretensões supostamente democráticas da arquitetura moderna. Como se sabe, esse debate foi notavelmente encenado na FAU-USP ao longo da década de 1960 através de uma confronto básico em torno das relações entre prática arquitetônica e revolução social (Arantes, 2002; Koury, 2003). De um lado, estava o arquiteto e professor Vilanova Artigas, um dos principais expoentes da arquitetura moderna no Brasil, mestre fundador da escola, que ocupava posição de liderança entre os arquitetos atuantes em São Paulo a partir dos anos 1940, e que atuava como mentor dos que estavam se formando nas décadas de $1950 \mathrm{e}$ 1960. Figura intelectual proeminente no interior do Partido Comunista Brasileiro (PCB), ele defendia a possibilidade de uma elite profissional oferecer soluções revolucionárias ao propor um desenho capaz de situar-se racionalmente entre intenções e meios (Artigas, 1967). Do outro lado estavam seus jovens discípulos Ferro, Lefèvre e Flávio Império (1935-1985), que haviam se reunido em um grupo chamado "Arquitetura Nova", enquanto iniciavam suas carreiras docentes na FAU. Em um momento no qual o país mais uma vez ingressava numa ditadura, eles desprezavam toda veleidade profissional como reveladora de compromissos maiores dos arquitetos com a modernização conservadora que localmente se aprofundava. De acordo com Ferro, os sinais aparentes de um desenvolvimento social falso ou não - do país entre as décadas de 1940 e 1960, "estimularam uma otimista atividade antecipadora": novos instrumentos de desenho haviam se mostrado necessários; os trabalhos de Niemeyer e Artigas eram as melhores expressões de uma tal abertura e coragem construtiva; Brasília assinalava o apogeu de tais esperanças nos avanços sociais, que logo se revelariam ilusórias com o toque militar de recolher. Jovens arquitetos como eles, contudo estavam começando a perceber a distância crescente entre $o$ amplo alcance de sua formação e expectativas e o estreitamento de suas tarefas profissionais:

"Ao adiamento de suas esperanças reagiram [esses jovens arquitetos], no primeiro instante, com a afirmação renovada e acentuada de suas posições principais. Daí esta espécie cabocla de brutalismo (oposto ao brutalismo estetizante europeu); esta didatização forçada de todos os procedimentos; a excessiva racionalização construtiva; o 'economismo' gerador de espaços ultra-densos raramente justificados por imposições objetivas, etc" (Ferro, 1967, 49).
É óbvio que não se tratava apenas de uma disputa entre duas gerações profissionais ou perspectivas disciplinares e poéticas distintas, mas a polêmica expressava um desacordo subjacente às esquerdas políticas do período acerca do caráter e do curso da revolução brasileira. De fato, as várias posições marxistas então em disputa pareciam concordar que ela deveria seguir o modelo clássico de uma revolução em duas etapas: um movimento de emancipação contra o imperialismo norte-americano, no qual os setores nacionalistas da burguesia urbana brasileira teriam o seu lugar na modernização das forças produtivas e dos direitos das classes trabalhadoras; e uma segunda etapa, que levaria à derrocada da ditadura militar no poder e o estabelecimento de um governo proletário revolucionário (Ridenti, 2010, 32-39). Apesar disso, para os militantes fiéis do PCB, como Artigas, aquela fase burguesa, patriótica e pacíica ainda estava em andamento; enquanto que para certos grupos dissidentes que emergiram depois do golpe de 1964 como a Ação Libertadora Nacional na qual Ferro e Lefèvre viriam a se engajar, este último também na Vanguarda Armada Revolucionária - esse primeiro estágio já estava superado, restando apenas a via armada socialista como única alternativa capaz de desbloquear a revolução anticapitalista brasileira.

De fato, naquelas circunstâncias, entre as múltiplas organizações revolucionárias existentes no país, a presença de arquitetos, artistas e intelectuais era um traço característico do PCB, da ALN e da VAR-Palmares. Mas, enquanto entre os membros do PCB prevalecia a ideia de um progresso técnico-industrial intrinsecamente neutro, a despeito de sua base de classe ou origens totalitárias; para aqueles que apoiavam a guerrilha urbana, o progresso material deveria necessariamente estar ligado à libertação do povo, uma posição que frequentemente os levaria a uma espécie de ceticismo acerca da modernização. Em meio a seus dilemas culturais, era possível encontrar tanto uma estética construtiva como programas mais inclinados ao popular ou a tradições pré-capitalistas (Ridenti, 2010, 71-80), que poderia inclusive encaminhar-se a um híbrido entre o pop ou tropicalista e a indústria cultural, combinando moderno e antigo, alto e baixo, cultura popular e deboche comercial, oscilando entre crítica, irreverência e integração (Schwarz, 1978, 73-78). Para Roberto Schwarz, mesmo o grupo intelectualizado de arquitetos em torno do "Arquitetura Nova" estaria sujeito a tais inflexões populistas no interior do marxismo brasileiro; a interrupção de uma perspectiva política ressoando em espaços torturados, "sobrecarregados de intenções", como em 
experimentos residenciais de classe média da década de 1960, elevados ao nível de "símbolo moralista e inconfortável de uma revolução que não houve" (Schwarz, 1978, 79).

O radicalismo crítico de Ferro é ilegível sem essa referência a uma agenda revolucionária. Afinal, para ele, as firmações estéticas, técnicas e industriais da arquitetura moderna tinham evidentes impactos sociais na atividade da construção e nas divisões de trabalho capitalistas correspondentes. Pois o comando despótico dos arquitetos modernos no canteiro de obras intensificava o enorme complexo de forças produtivas que estavam condenando progressivamente e violentamente milhões de trabalhadores à exploração lucrativa. Ferro, na verdade, repropunha assim a análise da arquitetura ao substituir o foco nas soluções de projeto nelas mesmas por um estudo das relações de produção no âmbito mais amplo da construção.

Desde 1968, Ferro vinha expandindo sua crítica do canteiro de obras para enfrentar o problema maior da produção arquitetônica em suas contradições econômicopolíticas (Arantes, 2002, 107). Em 1972, já na França, para onde se transferira em razão da perseguição política, ele destacou as complexas relações entre arquitetura, produção e consumo na educação dos arquitetos. Seguindo de perto a teoria da cooperação e da divisão do trabalho de Marx, Ferro passa a reconhecer a natureza conservadora da produção arquitetônica como um tipo de manufatura. A construção de um edifício tinha algumas características próprias: grande número de trabalhadores empregados simultaneamente, amplamente segmentados e hierarquicamente divididos para produzir a mesma mercadoria; a presença tanto dos ofícios manuais como dos meios industriais no processo da construção; domínio despótico de um capitalista, gerentes, inspetores, supervisores, ou de contramestres, empreiteiros e projetistas; a pretensa e ineficiente separação entre arte e técnica, arquitetura e práticas de construção, etc (Ferro, 1972, 203-207). Mais do que isso, a condenação do despotismo do arquiteto ligava-se à crítica da atividade do desenho como privilégio:

"Estes esquemas, desprovidos de realidade, abstratos, primariamente funcionais e mecânicos, não refletindo um projeto coletivo, dão muito mais a imagem daqueles que os fazem que do objetivo suposto; nada mais autoritário que tais proposições permitidas somente por uma posição privilegiada" (Ferro, 1972, 208).
Enquanto programa de ensino a ele encomendado pela Escola de Arquitetura de Grenoble, é compreensível, no texto, o quadro histórico e estrutural em que o autor propõe situar a manufatura arquitetônica. Seu radicalismo, no entanto, deriva diretamente de seu trabalho anterior em São Paulo como professor da FAU, membro de um grupo notável de leitores de "O Capital" na USP, além de um ativista comprometido com a revolução socialista no Brasil, que cedo o levaria a ser preso, torturado, processado e impedido de lecionar, antes de exilar-se na França.

Muitas dessas ideias iriam chegar à maturidade apenas em 1976, quando Ferro começou a publicar no Brasil partes de um livro que ele vinha escrevendo na França, e que o tornaria um dos mais penetrantes teóricos brasileiros da arquitetura de todos os tempos. O Canteiro e o Desenho, publicado pela primeira vez em livro em 1979, não é de modo algum uma análise da arquitetura brasileira. Retornando à teoria do valor de Marx e à leitura da produção cultural pela Escola de Frankfurt, assim como a toda uma série de estudos em sociologia do trabalho e filosofia da técnica, o autor toma a modernidade em geral e o processo de racionalização para situar o status do desenho de arquitetura como "mediação insubstituível para a totalização da produção sob o capital" por meio das divisões estabelecidas entre o fazer e o pensar, o dever e o poder, o labor manual e o trabalho intelectual. No começo do livro, ele reconhece o impacto da obra publicada em 1973 por Andre Gorz, Critique de la Division du Travail, como uma via de estudo do fetichismo da mercadoria, da alienação e da forclusão no âmbito da produção arquitetônica: o desenho, como a ciência e a tecnologia, não é de modo algum neutro, mas "o molde onde o trabalho idiotizado é cristalizado" (Ferro, 1979, 110; Ferro, 2011, 115). Afinal, "se o desenho se põe como móvel imediato da produção e se imprime nela seu guião simbólico, é porque é materialização da separação, reificação da ruptura" (Ferro, 1977, 79; 1979, 159). Ou ainda, o desenho é:

"parte indispensável da direção despótica. Aliás, falar de desenho como o conhecemos é conotar simultaneamente dependência e despotismo. (...) Porque não é senão como razão separada da concreção, efeito da ruptura da produção pela violência, que foi feito o que é: parte que, por ser parte, é dominada e transmite para baixo as formas da força sob a qual aparece, sofre e governa. (...) O desenho é uma das corporificações da heteronomia do canteiro. (...) É caminho obrigatório para a extração de mais-valia e não pode ser separado de qualquer outro desenho para a produção" (Ferro, 1979, 107-108). 
Não haveria qualquer outra forma de decifrar a farsa da arquitetura senão referindo-se à sua produção material e ao seu papel na produção do espaço como valor de troca. Na verdade, leitor de Panofsky, Blunt e Tafuri, essa hipótese geral era referida a toda a história da perspectiva, desde sua invenção no Renascimento até sua história contraditória na primeira era da máquina, para empregar a categoria de Reyner Banham, de Michelangelo a Le Corbusier e além (Ferro, 2010, 193200). Em um trabalho publicado muito depois, o autor especifica sua própria escoIha metodológica. Para ele, arquitetura teria sempre sido marcada pelas complexidades e tensões no interior de sua produção e deveria sempre ser encarada como um todo dialético, envolvendo esquemas e projetos arquitetônicos, investimento material, execução, recepção, uso e gestão. Nenhuma análise de uma obra de arquitetura deveria, portanto, focar apenas no objeto, mas em toda essa gênese construtiva dentro de um conjunto de trabalhos humanos, relações de trabalho e a economia política (Ferro, 1996).

Um tal enquadramento teórico teria, é claro, grande impacto na crítica da arquitetura brasileira contemporânea, marcada por enormes desigualdades entre a elite local de arquitetos "maneiristas", esteticamente atualizados e, até mesmo, inovadores, e uma gigantesca força de trabalho não-qualificada, esmagada por algumas das mais terríveis relações de produção e destituída de todos os benefícios da modernização. Tributário de um debate brasileiro e latino-americano mais amplo acerca do subdesenvolvimento enquanto parte do desenvolvimento desigual do mundo capitalista, Ferro iria claramente alinhar-se às classes trabalhadoras, investindo em dispositivos que ele reconheceria como revolucionários, por exemplo: o inevitável trabalho manual no interior da manufatura como uma forma possível de consciência material, física e corporal do trabalhador; a abertura ao improviso e à autodeterminação da produção; a liberação de tensões antagônicas; a associação livre entre grupos de produtores de modo a ultrapassar separações; em síntese, a superação de um desenho para a produção em nome de um desenho da produção, com toda a sua mutabilidade, descontinuidade e participação coletiva (Arantes, 2004, 117-119, 180). Se à época, hipóteses de atuação projetual como essas eram ainda muito tateantes, e pouco representativas no âmbito da produção contemporânea, elas parecem claramente emergir de uma avaliação lúcida, ainda que trágica dos dilemas postos ao trabalho dos arquitetos em um país como o Brasil.

\section{Arte, Matéria e Radicalismo}

Não resta dúvidas da persistência de representações radicais, ainda hoje muito potentes no sistema arquitetônico brasileiro e operativas na memória, no imaginário e nas aspirações coletivas dos arquitetos. Elas certamente variaram em termos de objetos, categorias, estratégias e discursos, e, eventualmente, renderam-se aos limites de seus registros históricos e escolhas teóricas. Mas é interessante perceber o quanto a tendência avançou no entendimento da arquitetura moderna como força global.

Tanto Mário Pedrosa como Sérgio Ferro foram fortemente marcados por seus contextos locais e tiveram que lidar com os dilemas econômicos, políticos e ideológicos contemporâneos no Brasil: fechamento e criatividade cultural, modernização e ditadura, industrialização e subdesenvolvimento. Contudo, em face do campo da arquitetura, suas abordagens parecem entre as mais inovadoras e revigorantes. Com efeito, tem sido frequentemente esquecida a sintonia de suas ideias com a estado de espírito internacional no que concerne à crítica e à produção arquitetônica. No caso de Pedrosa: a fadiga com o funcionalismo, a referência prematura à teoria de Gestalt para enfrentar questões estéticas, o apelo à nova monumentalidade e à arte pública, o conceito de modernidade como projeto inacabado, móvel e sempre surpreendente. No caso de Ferro: a investigação do desenho e do canteiro como parte da economia política e das micro-divisões de trabalho, a aproximação a Hegel, Marx e múltiplas fontes do marxismo, da psicanálise, da semiótica, do estruturalismo e do pós-estruturalismo, a proposta de uma prática arquitetônica crítica, reflexiva, ou não-projetada.

Na verdade, a ênfase do primeiro no poder estético e na relevância pública da arquitetura, e a obsessão do segundo com as relações materiais nas quais a arquitetura inevitavelmente está envolvida, parece ter iluminado áreas ainda hoje negligenciadas pela maior parte das críticas contemporâneas de arquitetura, principalmente focadas na obra em si dos arquitetos, em termos tecnológicos, formais ou espaciais, ou em seu embate com o entorno, as pré-existências, repertórios disciplinares herdados ou partilhados, cânones ou formas de apropriação. Suas abordagens, nesse sentido, não são apenas relevantes para o entendimento da produção arquitetônica em um país em desenvolvimento como o Brasil, mas parecem ampliar sensivelmente as perspectivas de análise crítica em qualquer lugar onde arte e trabalho se desenvolveram em termos modernos, isto é, entrincheira- 
dos por contradições. É claro, Pedrosa havia imortalizado a ideia paradoxal do Brasil como um país condenado à modernidade; livre de velhas tradições e de uma identidade nacional estável, não haveria outro futuro para o país do que se engajar e interferir criticamente nas tendências universais da arte, da arquitetura e da civilização. Apontava assim para uma ruptura com os recortes nacionais típicos dos exames da produção periférica, assim como com leituras da arquitetura pela arquitetura. Para Ferro, qualquer projeto de emancipação, ou qualquer tipo de projeto experimental deveria ser testado em face das relações sociais de produção que o mesmo propunha ou englobava. Nessa linha, os arquitetos - brasileiros ou não - jamais deveriam fiar-se confortavelmente em conquistas prévias, ou puramente eruditas, ocidentais etc, mas sempre ir em busca de valores de inventividade, consciência e emancipação, seja em estética seja em política. Esses, como tantos outros, são certamente resultados tão produtivos em termos cosmopolitas quanto localmente enraizados. A despeito de suas estranhas contingências e obstáculos, é provavelmente aí que eles oferecem grandes contribuições à crítica e às práticas radicais contemporâneas.

\section{Referências}

Andrade, M. de. (1944) Brazil Builds, in: Folha da Manhã, São Paulo, 23. Mar. 1944. Arantes, O.B.F. (1991). Mário Pedrosa: itinerário crítico. São Paulo: Editora Página Aberta.

Arantes, O.B.F. (1995). Dados biográficos (cronologia), in: Pedrosa, Mário. Política das artes. São Paulo: Editora da Universidade de São Paulo, pp. 349-363.

Arantes, P.F. (2002). Arquitetura Nova: Sérgio Ferro, Flávio Império e Rodrigo Lefèvre, de Artigas aos mutirões. São Paulo: Editora 34.

Arantes, P.F. (2004). Reinventing the building site, in Forty, A.; Andreolli, E. (Orgs.). Brasil's Modern Arquitetura. Londres: Phaidon, pp. 170-201.

Artigas, J.B.V. (1952). Os Caminhos da Arquitetura Moderna, in: Caminhos da Arquitetura. São Paulo: Cosac Naify, 2004, pp. 31-50.

Artigas, J.B.V. (1954). Considerações Sobre Arquitetura Brasileira, in: Caminhos da Arquitetura. São Paulo: Cosac Naify, 2004, pp. 51-55.

Artigas, J.B.V. (1967). O Desenho, in: Caminhos da Arquitetura. São Paulo: Cosac Naify, 2004, pp. 108-118.

Candido, A. (1967) Literatura e cultura de 1900 a 1945, in: Literatura e Sociedade. São
Paulo: Companhia Editora Nacional, pp. 127-160.

Candido, A. (1973) Literatura e subdesenvolvimento, in: Argumento, n. 1, out. 1973, pp. 624.

Candido, A. (1995). Radicalismos, in: Vários Escritos. São Paulo: Duas Cidades.

Cappello, M.B.C. (2006). Arquitetura em Revista: arquitetura moderna no Brasil e sua recepção nas revistas francesas, inglesas e italianas (1945-1960). São Paulo, Universidade de São Paulo (Doutorado).

Chakrabarty, D. (2000). "Historicism and the narration of modernity", in Provincializing Europe. Princeton: Princeton University Press, pp. 27-113.

Costa, L. (1952). Arquitetura Brasileira. Rio de Janeiro: Ministério da Educação e Saúde.

Dedecca, P.G. (2012). Sociabilidade, Crítica e Posição: o meio arquitetônico, as revistas especializadas e o debate do moderno em São Paulo (1945-1965). São Paulo: Universidade de São Paulo (Mestrado).

Ferro, S. (1967). Arquitetura Nova, in: Ferro, S. Arquitetura e trabalho livre. São Paulo: Cosac Naify, 2006, pp. 47-58

Ferro, S. (1977). II - O Desenho; Almanaque No. 3, pp. 74-101.

Ferro, S. (1979). O Canteiro e o Desenho. São Paulo: Cosac Naify, 2006.

Ferro, S. (1994). Programa para polo de ensino, pesquisa e experimentação da construção, in: Ferro, S. Arquitetura e trabalho livre. São Paulo: Cosac Naify, 2006, pp. 222-232.

Ferro, S. (1996). Questões de método, in: Ferro, S. Arquitetura e trabalho livre. São Paulo: Cosac Naify, 2006, pp. 233-240.

Ferro, S. (2010). A história da arquitetura vista do canteiro: três aulas de Sérgio Ferro. São Paulo, FAU-USP.

Ferro, S. (2011) História da arquitetura e projeto da história, entrevista a Felipe Contier. Designio, Ns. 11-12, pp. 113-126.

Ferro, S; Lefèvre, R. (1963). Proposta inicial para um debate: possibilidades de atuação, in: Ferro, S. Arquitetura e trabalho livre. São Paulo: Cosac Naify, 2006, pp. 33-36.

Ferro, S; Lefèvre, R.; Império, F. (1965). Arquitetura experimental, in: Ferro, S. Arquitetura e trabalho livre. São Paulo: Cosac Naify, 2006, pp. 37-44.

Fiammenghi, J.B. (2020). Max Bill, a crítica e o ensino de arquitetura no Brasil, 19481962. São Paulo, FAU-USP (Trabalho Final de Graduação).

Gabriel, M.F. (2017) Mário Pedrosa e a arquitetura brasileira: autonomia e síntese das artes. São Paulo, FAU-USP (Doutorado).

Goodwin, P. (1943). Brasil Builds: arquitetura new and old, 1652-1942. New York: MoMA. 
Junqueira, M. (2009). Poéticas da razão e construção: conversa de paulista. São Paulo: Universidade de São Paulo (Livre Docência).

Koury, A. P. (2003). Grupo Arquitetura Nova: Flávio Império, Rodrigo Lefèvre e Sergio Ferro. São Paulo: Romano Guerra/ Edusp/ Fapesp.

Liernur, J. F. (1999). The South American way; Block No.4, pp. 23-41.

Martins, C. A. F. (1999). Hay algo de irracional...; Block No.4, pp. 8-22.

Mesquita, A.M. (2011). A presença estrangeira em Habitat (1950-54) e Mirante das Artes, Etc. (1967-68), in: Lanna, A.; Peixoto, F.; Lira, J.; Sampaio, M.R.A. (Orgs). São Paulo, os estrangeiros e a construção das cidades. São Paulo: Alameda, pp. 521-542.

Niemeyer, O. (1958). Depoimento; Módulo No. 9, pp. 3-6.

Nobre, A.L. (2008). Fios Cortantes: projeto e produto, arquitetura e design no Rio de Janeiro (1950-1970). Rio de Janeiro: PUC-RJ (Doutorado).

Pedrosa, M. (1933). As tendências sociais da arte e Käthe Kollwitz, in: Política das artes: textos escolhidos I. São Paulo: Edusp, 1995, pp. 35-56.

Pedrosa, M. (1943). Portinari: de Brodósqui aos murais de Washington, in: Dos Murais de Portinari aos Espaços de Brasília. São Paulo: Perspectiva, 1981, pp. 7-25.

Pedrosa, M. (1944). Calder, escultor de cata-ventos, in: Modernidade cá e lá: textos escoIhidos IV. São Paulo: Editora da Universidade de São Paulo, 2000, pp. 51-66.

Pedrosa, M. (1947). Pela independência da arte, in: Política das artes: textos escolhidos I. São Paulo: Editora da Universidade de São Paulo, 1995, pp. 67-68.

Pedrosa, M. (1952a). Arte e revolução, in: Política das artes: textos escolhidos I. São Paulo: Editora da Universidade de São Paulo, 1995, pp. 95-98.

Pedrosa, M. (1952b). Espaço e Arquitetura, in: Dos Murais de Portinari aos Espaços de Brasília. São Paulo: Perspectiva, 1981, pp. 251-254

Pedrosa, M. (1953a). A arquitetura moderna no Brasil, in: Dos Murais de Portinari aos Espaços de Brasília. São Paulo: Perspectiva, 1981, pp. 255-264

Pedrosa, M. (1953b). Arquitetura e atualidade. in: Dos Murais de Portinari aos Espaços de Brasília. São Paulo: Perspectiva, 1981, pp. 265-268.

Pedrosa, M. (1957a). Arquitetura e crítica de arte I, in: Dos Murais de Portinari aos Espaços de Brasília. São Paulo: Perspectiva, 1981, pp. 269-271.

Pedrosa, M. (1957b). A crítica de arte na arquitetura, in Dos Murais de Portinari aos Espaços de Brasília. São Paulo: Perspectiva, 1981, pp. 273-275.

Pedrosa, M. (1957c). Arquitetura e crítica de arte II, in: Dos Murais de Portinari aos Espaços de Brasília. São Paulo: Perspectiva, 1981, pp. 277-279.

Pedrosa, M. (1957d). O ponto de vista do crítico, in: Política das artes: textos escolhidos I.
São Paulo: Editora da Universidade de São Paulo, 1995, pp. 161-164.

Pedrosa, M. (1957e). Reflexões em torno da nova capital, in Dos Murais de Portinari aos Espaços de Brasília. São Paulo: Perspectiva, 1981, pp. 303-316.

Pedrosa, M. (1958a). O depoimento de Oscar Niemeyer - I, in: Dos Murais de Portinari aos Espaços de Brasília. Aracy Amaral, org., São Paulo: Perspectiva, 1981, pp. 289-291.

Pedrosa, M. (1958b). Utopia - obra de arte, in: Dos Murais de Portinari aos Espaços de Brasília. Aracy Amaral, org., São Paulo: Perspectiva, 1981, pp. 317-319.

Pedrosa, M. (1959). Introdução à arquitetura brasileira II, in: Dos Murais de Portinari aos Espaços de Brasília. São Paulo: Perspectiva, 1981, pp. 329-335.

Pedrosa, M. (1973). A bienal de cá para lá, in: Política das artes: textos escolhidos I. São Paulo: Editora da Universidade de São Paulo, 1995, pp. 217-284.

Ridenti, M. (2010). O fantasma da revolução brasileira. 2a. ed. São Paulo: Ed. Unesp.

Schwarz, R. (1994). Pelo prisma da arquitetura, in: Sequências Brasileiras. São Paulo Companhia das Letras, 1999, pp. 199-204.

Schwarz, R. (1978). Cultura e Política, 1964-1969, in O Pai de família e outros estudos. Rio de Janeiro: Paz e Terra, pp. 61-92.

Scott, G. (1914). The Arquitetura of Humanism: a study in the history of taste. Boston: Houghton Mifflin Company

Silva, N. M. da (2017). As revistas Acrópole e Habitat e a consolidação da Arquitetura Moderna Brasileira (1950-1956). São Carlos, SP, IAU-USP (Mestrado)

Stuchi, F.T. (2007) Revista Habitat: um olhar moderno sobre os anos 50 em São Paulo. São Paulo, FAU-USP (Mestrado)

Tinem, N. (2006). O Alvo do Olhar Estrangeiro: o Brasil na historiografia da arquitetura moderna. João Pessoa: Ed. Universidade Federal da Paraíba.

Vasconcelos, S. de (1957). Critica de arte e arquitetura; AD No. 24.

Xavier, A. (2003). Depoimento de uma geração. São Paulo: Cosac Naify.

Zein, R. V. (2005). A arquitetura da escola paulista brutalista 1953-1973. Porto Alegre, Universidade Federal do Rio Grande do Sul (Doutorado). 